\title{
The Role of $\beta$-Blockers in Melanoma
}

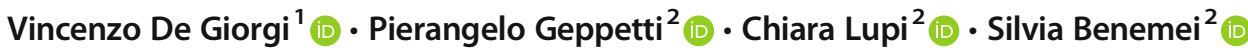

Received: 1 May 2019 / Accepted: 15 August 2019

(C) Springer Science+Business Media, LLC, part of Springer Nature 2019

\begin{abstract}
Melanoma is one of the most aggressive and less chemotherapy-responsive human cancers, representing a major public health issue worldwide. The early diagnosis still represents the best approach in order to reduce mortality, especially in advanced stages. Preclinical evidence, collected through several in vitro and in vivo models, has been accumulating about the pathophysiological involvement of $\beta$-adrenoceptors in melanoma progression. This involvement has been paralleled by the evidence that drugs blocking $\beta$-adrenoceptors ( $\beta$-blockers) may have a relevant role in the treatment of melanoma and in the prevention of its progression. $\beta$-blockers are a class of drugs extensively used in clinical practice, not limited to cardiovascular therapeutics. Evidence collected through retrospective and prospective observational studies suggests that treatment with $\beta$-blockers, mainly propranolol, is able to delay melanoma progression. Although conclusive evidence is still lacking, current knowledge proposes $\beta$ blockers as an opportunity for antitumor treatment in melanoma. Clinical trials are needed in order to prove their claimed efficacy.
\end{abstract}

Keywords Melanoma $\cdot \beta$-adrenoceptors $\cdot$ Propranolol $\cdot$ Adrenaline $\cdot$ Noradrenaline

\section{Introduction}

The incidence of skin cancers has been increasing over the past decades. Currently, between 2 and 3 millions nonmelanoma skin cancers and 132,000 melanoma skin cancers occur globally each year (WHO-Skin cancer 2019). Melanoma is among the most aggressive and chemotherapyresistant human cancers, representing a major public health problem worldwide. Although immunotherapy (e.g. tyrosine kinase inhibitors, new immunotherapy agents) has expanded treatment options for cancers with historically poor outcomes like melanoma, a relevant proportion of patients still fail to experience long-lasting clinical benefit. Early detection still represents the best means to reduce mortality due to this tumor, especially in advanced stages (Maverakis et al. 2015).

Vincenzo De Giorgi

vincenzo.degiorgi@unifi.it

1 Division of Dermatology, Department of Surgery and Translational Medicine, University of Florence, Largo Brambilla 3, 50134 Florence, Italy

2 Headache Centre, Careggi University Hospital, Department of Health Sciences, University of Florence, Viale Pieraccini 6, 50139 Florence, Italy
Over the last 30 years, a substantial body of clinical and epidemiological research has linked psychosocial factors, including stress, depression and lack of social support, with cancer onset and progression (Sanzo et al. 2010; Jia et al. 2017; Spiegel 1994). Stress occurs when the organism perceives a disruption or a threat of disruption of homeostasis (Krizanova et al. 2016), and stress response is constituted by the constant adaptation of the organism in order to maintain the homeostasis in answer to changes in social and physical environments (Goldstein 2003). While acute, short-term stress is considered to have a positive effect on the body, chronic stress is usually detrimental and may result in serious health consequences. Prolonged stress is associated with dysregulation of the hypothalamic-pituitary-adrenal axis, leading to an increase in the production of cortisol and simultaneous elevations in catecholamines, i.e. adrenaline and noradrenaline (Krizanova et al. 2016). The effects of catecholamines are mediated through interactions with $\alpha$ - and $\beta$-adrenoceptors (ARs). Many studies suggest that stress-related catecholamines overproduction might impact cancer prognosis and mortality, affecting not only the antitumor immune response (Marino and Cosentino 2013), but also displaying direct tumor-promoting effects in breast, ovary, colorectal, esophagus, lung, prostate, nasopharynx cancers, as well as in leukemia and angiosarcoma (Tang et al. 2013). As shown by a large body of preclinical evidence, $\beta$-ARs are widely involved in 
the regulation of these pro-tumorigenic cellular processes. Their activation by catecholamines seems to stimulate cancer cell proliferation, to induce anti-apoptotic processes, to promote angiogenesis and to facilitate migration, invasion and adhesion of tumor cells, finally leading to metastasis (Tang et al. 2013), Fig. 1. However, there is no firm conclusion that $\beta$-ARs are the fundamental pathway on these processes. $\alpha$ ARs have been found in tumors, such as prostate cancer, malignant mesothelioma, thyroid medullary carcinoma, and breast cancer, and their activation may affect cancer progression as well (Hirota 2016). The presence and the strength of AR-mediated pro-tumorigenic mechanisms is influenced by the quantity and subtype of AR expressed by each kind of tumor. With regard to melanoma, functional $\beta$-ARs have been found in this cancer (Yang et al. 2009; Moretti et al. 2013; Calvani et al. 2015), while there is no similar evidence about $\alpha$-AR expression. Interestingly, each of the reported protumorigenic effects caused by $\beta$-adrenergic stimulation on melanoma and microenvironment cells was reduced by a direct blockade of $\beta$-ARs using their selective blocking agents (Yang et al. 2009; Moretti et al. 2013; Calvani et al. 2015; Dal Monte et al. 2013).

In the light of such promising laboratory data, many researchers have suggested that the commonly prescribed class of $\beta$-AR antagonist drugs, the $\beta$-blockers, may positively impact on cancer survival. In the last few years, a growing number of observational studies have supported the use of $\beta$-blockers as an off-label adjuvant therapy capable of prolonging survival of cancer patients, although some studies have put forward controversial conclusions, as recently highlighted in three different meta-analysis (Weberpals et al. 2016; Na et al. 2018; Yap et al. 2018). In dermatology, the use of $\beta$-adrenergic-blocking agents has risen in popularity since the serendipitous discovery of their efficacy in cases of severe infantile hemangiomas (LeauteLabreze et al. 2008). Similar to what observed in other cancer types, the main results of cohort studies in patients affected by melanoma seem to confirm the association between $\beta$-blocker assumption and reduction of disease progression (De Giorgi et al. 2011, 2013, 2017, 2018; Lameshow et al. 2011), despite some discrepancies exist between the studies conducted so far (Livingstone et al. 2013; McCourt et al. 2014). However, $\beta$ blockers still cannot be considered as an alternative to traditional therapy, as they are investigational, not yet have reached the clinic with anti-cancer intent and even may be of value when actually added to traditional therapy such as chemotherapy.

Taking into account the solid preclinical data, this review aims to present the current clinical evidence about antitumor efficacy of $\beta$-blockers in the treatment of melanoma, in order to discuss whether these drugs can be considered an appropriate therapeutic option for patients affected by this skin cancer.

\section{Beta-Adrenergic System and Pharmacology of $\beta$-Blockers}

Adrenaline is synthetized from noradrenaline through demethylation by chromaffin cells in the adrenal medulla and released in the bloodstream upon stimulation by the sympathetic nervous system. Noradrenaline is a neurotransmitter in the central and peripheral nervous system. At a central level, it is mainly involved in the regulation of blood pressure by the vasomotor center within the medulla, but also in the induction of wakefulness and state of alertness, and in the control of mood state and pain circuits (pain descending control). In peripheral tissues, noradrenaline is the main transmitter of sympathetic postganglionic fibers (Katzung 2012; Coelho et al. 2017).

Catecholamines exert their actions by interacting with 7transmembrane, G protein-coupled receptors named ARs, widely expressed in the target tissues. The general class of AR is constituted by $\alpha$ - and $\beta$-AR types, each further subdivided in subtypes. Three different $\beta$-AR receptors $(\beta 1$, $\beta 2$ and $\beta 3-A R)$ have been identified in humans. Usually, $\beta 1-$ AR are located close to sympathetic terminals and are targeted mainly by noradrenaline released from nerves, while $\beta 2$-AR are often extrajunctional receptors and may be preferentially activated by circulating noradrenaline and adrenaline. In
Fig. 1 Proposed mechanism of $\beta$-adrenoceptors in cancer progression and relative role of $\beta$-blockers

\section{Activation of beta-adrenoceptor}

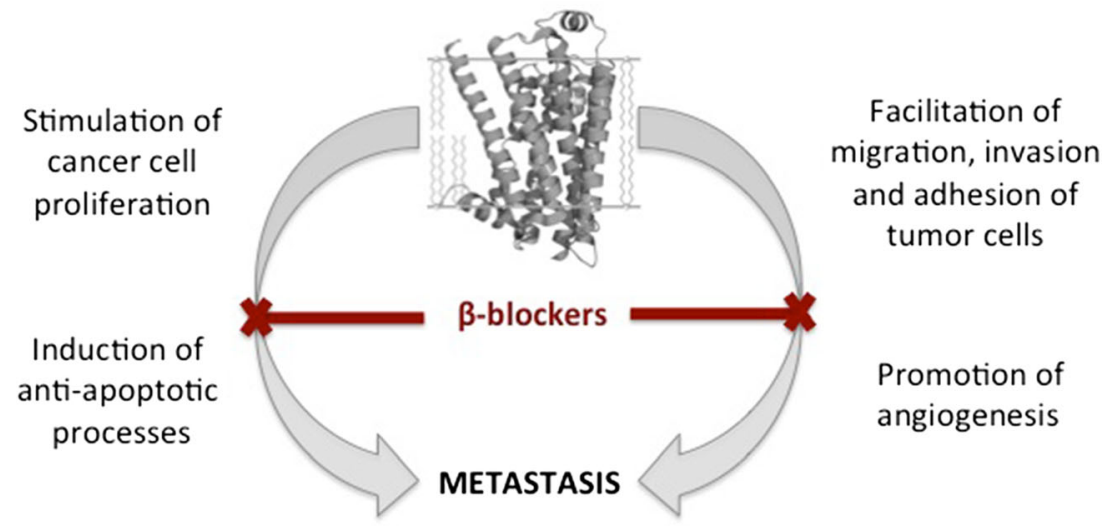


particular, $\beta$-AR are expressed in heart ( $\beta 1$ and a few $\beta 2$, increasing force and rate of contraction), in skeletal muscle ( $\beta 2$, inducing hypertrophy), and in vascular smooth muscle and smooth muscular organs, such as bronchi, uterus, gastrointestinal tract and urinary bladder ( $\beta 2$, promoting relaxation). $\beta$-AR are also implicated in metabolic and endocrine effects, as far as $\beta 2$-AR activation induces insulin and glucagon secretion, liver gluconeogenesis and glycogenolysis, and muscular glycogenolysis, while $\beta 1$-AR activation determines renin release by the juxtaglomerular cells of kidney (LópezSendón et al. 2004. $\beta 3$-AR, that are more sensitive to the action of noradrenaline, are mainly expressed in brown adipose tissue, where they activate lipolysis together with $\beta 1$ $\mathrm{AR}$, and in skeletal muscle, where they contribute to thermogenesis (Balligand 2013). Beta2-AR are also expressed on skin, where they can be found in secretory coil of apocrine glands, keratinocytes, fibroblasts and melanocytes (Chen and Tsai 2017).

Beta-blockers share the common feature of antagonizing the effects of adrenergic stimuli on various organs. They reversibly bind $\beta$ receptors and competitively reduce receptor occupancy by catecholamines and other $\beta$ agonists. On the basis of the relative affinity for the different receptor subtypes, $\beta$-blockers can be broadly classified into non-selective, those producing a competitive blockade of both $\beta 1$ - and $\beta 2-\mathrm{AR}$, and $\beta 1$-selective, those with much higher affinity for the $\beta 1$ than for the $\beta 2$ receptors usually. However, since none of the clinically available $\beta$-blockers are absolutely specific for $\beta 1$ receptors, the selectivity is dose-dependent and decreases or disappears when larger doses are used (Westfall and Westfall 2011). Few molecules (e.g. propranolol, nadololol, levobunolol, bupranolol) have been shown to target $\beta 3$-AR, to this day (Bond et al. 2019). Although most of the effects of $\beta$-blockers are due to $\beta$-AR blockade, some actions may be due to other pharmacodynamic properties. Several selective or non-selective $\beta$-blockers present peripheral vasodilator activity produced through different pathways, such as $\alpha 1$-AR blockade, $\beta 2$-agonism or mechanisms independent of the interaction with ARs (i.e. release of nitric oxide, antioxidant action, $\mathrm{K}^{+}$channel opening, and $\mathrm{Ca}^{2}{ }^{+}$entry blockade). Most $\beta$-blocking drugs in clinical use are pure antagonists, but paradoxically some $\beta$-blockers exert a weak agonist response, defined as partial agonism or intrinsic sympathomimetic activity (ISA), and can moderately stimulate (in the absence of catecholamines) and block (in the presence of high catecholamine concentrations) $\beta$-ARs (López-Sendón et al. 2004; Baker 2005; Westfall and Westfall 2011) (Table 1). Furthermore, evidence suggests that some $\beta$ blockers (i.e. propranolol, timolol) are inverse agonist drugs that reduce constitutive activity of $\beta$-AR in some tissues (Chidiac et al. 1994) (see Table 1).

The differences in lipid solubility influences the pharmacokinetic profile of various $\beta$-blockers. Lipophilic drugs (e.g. metoprolol, propranolol, timolol) are rapidly and completely absorbed from the gastrointestinal tract and extensively metabolized in the gut wall and in the liver (first pass effect), so that their oral bioavailability is low (10-30\%). They present short elimination half-lives (1-5 h) and easily enter the central

Table 1 Main pharmacologicaland pharmacokinetic properties of $\beta$-blockers (Westfall and Westfall 2011; López-Sendón et al. 2004)

\begin{tabular}{|c|c|c|c|c|c|c|}
\hline$\beta$-blocker & ISA & Vasodilator activity & Lipid solubility & $\begin{array}{l}\text { Absorption } \\
(\%)\end{array}$ & $\begin{array}{l}\text { Oral bioavailability } \\
(\%)\end{array}$ & $\begin{array}{l}\text { Plasmatic } \\
\text { half-life (hours) }\end{array}$ \\
\hline \multicolumn{7}{|c|}{ Non-selective $\beta$-blockers } \\
\hline Nadolol & 0 & & Low & 30 & $30-50$ & $20-24$ \\
\hline Penbutolol & + & & High/Moderate & $\sim 100$ & $\sim 100$ & $\sim 5$ \\
\hline Pindolol & +++ & & Low/High & $>95$ & $\sim 100$ & $3-4$ \\
\hline Propranolol & 0 & & High & $<90$ & 30 & $3-5$ \\
\hline Timolol & 0 & & Low-moderate/High & 90 & 75 & 4 \\
\hline Carvedilol & 0 & $\begin{array}{l}\alpha 1 \text {-AR blockade, antioxidant activity, } \\
\text { Ca2 + entry blockade }\end{array}$ & Moderate & $>90$ & $\sim 30$ & $7-10$ \\
\hline Labetalol & + & $\alpha 1-\mathrm{AR}$ blockade & Low & $>90$ & $\sim 33$ & $3-4$ \\
\hline \multicolumn{7}{|c|}{ Selective $\beta 1$-blockers } \\
\hline Acebutolol & + & & Low/Moderate & 90 & $20-60$ & $3-4$ \\
\hline Atenolol & 0 & & Low & 90 & $50-60$ & $6-7$ \\
\hline Bisoprolol & 0 & & Moderate & $\leq 90$ & 80 & $9-12$ \\
\hline Esmolol & 0 & & Low & NA & NA & 0.15 \\
\hline Metoprolol & 0 & & High & $\sim 100$ & $40-50$ & $3-7$ \\
\hline Celiprolol & 0 & Release of NO, $\beta 2$-AR agonism & Moderate & $\sim 74$ & $30-70$ & 5 \\
\hline Nebivolol & 0 & Release of NO & Low & NA & NA & $11-30$ \\
\hline
\end{tabular}

$A R$ adrenoceptor, ISA intrinsic sympathomimetic activity, $N A$ not available, $N O$ nitric oxide 
nervous system, which may account for a greater incidence of central side-effects. Hydrophilic $\beta$-blockers (e.g. atenolol, esmolol) that are absorbed incompletely from the gastrointestinal tract, are excreted unchanged or as active metabolites by the kidney. These molecules have longer half-lives, and barely cross the blood-brain barrier (López-Sendón et al. 2004; Westfall and Westfall 2011) (Table 1).

The major pharmacological effects of $\beta$-blockers are documented in the cardiovascular system, with important differences between the effects induced in the heart in healthy subjects at rest versus in conditions of stress, such as exercise or the presence of cardiovascular disease. In the context of cardiovascular diseases, these drugs have proved to be effective in hypertension, stable and acute coronary artery disease, hearth failure and cardiac arrhythmias. Since their arrival on the clinical scene in $1960 \mathrm{~s}$, the breadth of $\beta$-blockers has expanded to include, inter alia, treatment of migraine, essential tremor, glaucoma, and control of somatic symptoms of hyperthyroidism and anxiety (Westfall and Westfall 2011).

Although $\beta$-blockers are generally well tolerated, sideeffects may occur, especially when these agents are used at larger doses. Common side effects include bradycardia, reduced capability to exercise, impotence and loss of libido, constipation or diarrhea. Sometimes patients note cold hands and feet. Central effects, such as fatigue, headache, insomnia and vivid dreams, are less common with hydrophilic molecules. Beta-blockers are contraindicated in patients with asthma or bronchospastic chronic obstructive pulmonary disease owing to concerns that these medications may trigger increase of airway resistance, and in people affected by diabetes, since $\beta$-blockers may mask warning symptoms of hypoglycemic episodes, such as tremor and tachycardia (López-Sendón et al. 2004; Westfall and Westfall 2011; Katzung 2012).

\section{$\beta$-Blockers and Cancer}

The first finding corroborating the involvement of $\beta-A R$ in cancer proliferation was the evidence that, on the one side, isoprenaline, a non-selective $\beta$-AR agonist, induces lung adenocarcinoma cell proliferation and, on the other side, propranolol contrasts the effect of $\beta$-AR stimulation (Schuller and Cole 1989). In the following years, evidence has been accumulating about similar properties in other types of cancer, including angiosarcoma, breast, colorectum, hemangiomas, leukemia, lung, melanoma, nasopharynx, esophagus, ovary, pancreas, prostate and stomach (Tang et al. 2013). Importantly from a therapeutic point of view, $\beta$-blockers may be effective in contrasting cancer development and progression. First, in rodent models of neuroblastoma, either nonselective or selective $\beta$ - blockers have been shown to boost the response to chemotherapy (Pasquier et al. 2013). Second, in an ovarian carcinoma mouse model, propranolol impairs the $\beta 2$-AR-mediated growth of cancer cells induced by increased noradrenaline associated with chronic stress (Thaker et al. 2006). Similarly, in a prostate cancer mouse model, selective $\beta 2$-AR blockade prevents the tumor growth favored by surgical stress (Hassan et al. 2013). Third, propranolol prevents tumor development in a mouse model of lung cancer (Min et al. 2016); it also suppresses proliferation and promotes apoptosis in hemangioma cells, similar to selective $\beta 2$-AR blockers, but not selective $\beta 1$-AR blockers (Munabi et al. 2016). A more relevant role for $\beta 2-A R$ in comparison to $\beta 1-A R$ is suggested also in other cancer models, as pancreatic cancer cell line invasiveness and proliferation are more efficiently blocked by $\beta 2$-AR blockers than by $\beta 1$-AR blockers (Zhang et al. 2010) and in a model of prostate cancer, $\beta 2-A R$ knockout mice in which the lack of $\beta 2-A R$ inhibits tumor progression (Zahalka et al. 2017).

\section{Beta-Blockers and Melanoma}

One seminal paper suggesting peculiar features of melanoma in comparison to other tumors regarding influences of catecholaminergic system is the oldest one retrieved searching the PubMed with the terms "melanoma" AND "noradrenaline" or "melanoma" AND "norepinephrine". The paper by Edlich et al. (Edlich et al. 1966) showed that, in rodents, changes in melanoma blood flow secondary to catecholamine infusion were more pronounced than those in the proximal skin and muscle. In particular, it was shown that the administration of low doses of adrenaline and noradrenaline was associated with a relevant reduction in tumor blood flow associated with unvaried skin blood flow. Similarly, the administration of higher doses of both substances reduced perfusion to all tissues, with much greater effects in the melanoma tissue. These results differentiated melanoma from other neoplasms (i.e. sarcoma and carcinoma) that were found to behave like normal tissue by other authors (Guillino and Grantham 1961, 1962). Importantly, it was already known that, as observed in mice through a transparent membrane inserted in a skin flap, the vascular system of the carcinoma and sarcoma was made of randomly sinusoidal channels of large diameter with no evidence of arterioles and venules, while melanoma had a quite organized vessel system with thinner capillaries and evidence of differentiation into arterioles and venules (Algire and Legallais 1951, 1958). Although initial suggestions emerging from evidence were primarily dealing with vessel anatomy and physiology, data collected since that remote beginning compose a more complex scenario in which catecholamines, and hence $\beta$-blockers, may exert differential effects in melanoma that may be exploited for therapeutic purposes. The following sections of the review will present evidence according to its preclinical (i.e. in vitro, in vivo) or 
clinical nature and will draw conclusion emerging from current knowledge on the field.

\section{Preclinical Evidence}

Preclinical evidence has been collected by means of different experimental approaches and models, spanning from cell lines to in vivo animal model.

\section{In Vitro}

\section{$\beta$-Adrenoceptors}

Benign melanocytic nevi, atypical nevi and malignant melanomas express $\beta 1$ - and $\beta 2$-ARs, with expression significantly higher in the latters (Rains et al. 2017). Immunohistochemistry assay has shown the presence of $\beta 1$ - and $\beta 2$-ARs in cell lines (C8161, 1174MEL, Me18105) and in primary and metastatic human melanoma biopsies (Yang et al. 2009). Importantly, noradrenaline upregulates production of (vascular endothelial growth factor) VEGF, interleukin-6 (IL-6) and interleukin-8 (IL-8), in cell lines by both $\beta 1$ and $\beta 2$ ARs (Yang et al. 2009). Accordingly, human A375 primary melanoma cell line and human Hs29-4 T metastatic melanoma cell lines have been shown to express $\beta 1$ - and $\beta 2$-ARs, measurable as both transcripts and proteins (Moretti et al. 2013); a previous binding study in the melanoma cell line A-375 has concluded that cells express a homogeneous population of $\beta 2$-adrenoceptors. (Steinkraus et al. 1990). Noteworthy, $\beta 3-\mathrm{AR}$ expression in mouse B16F10 melanoma cells was demonstrated (Dal Monte et al. 2013) and more importantly from a therapeutic point of view, immunohistochemical research of $\beta 1$-ARs, $\beta 2$-ARs, and $\beta 3$-ARs across 29 of the most common human cancers (389 tissues total) and 19 matching non-cancer controls (100 tissues total) has proven that all three $\beta$-AR receptors, and in particular $\beta 3$-AR receptors, were expressed most strongly in melanoma in comparison to other cancers (Rains et al. 2017). Recently, it has been also shown that $\beta 3$-AR promotes a metabolic shift, with accelerated glycolysis and reduced mitochondrial activity, in both melanoma and embryonic stem cells, through the induction of uncoupling protein 2 (UCP2). In particular, the $\beta 3-\mathrm{AR} / \mathrm{UCP} 2$ axis induces a strong reduction of mitochondrial activity by reducing ATP synthesis and mitochondrial reactive oxygen species (mtROS). Importantly, $\beta 3$-AR have been demonstrated within the mitochondrial membrane in melanoma cells, where they can control of mitochondrial dormancy (Calvani et al. 2018). In addition, $\beta 3$ ARs are expressed in vivo in stromal, inflammatory and vascular cells of the melanoma microenvironment. It has been shown that the coexistence of $\beta 3-\mathrm{AR}$ in melanoma and accessory cells is the substrate needed to drive melanoma cells responses to environmental stimuli, to increase melanoma cells responses to macrophages and stromal fibroblasts, to promote melanoma cell motility and to induce stem-like traits. Noteworthy, $\beta 3-\mathrm{AR}$ activation in melanoma accessory cells induces pro-inflammatory cytokines secretion and neoangiogenesis that support tumor growth and melanoma aggressiveness (Calvani et al. 2015). $\beta 3$-ARs also play a pivotal role in the recruitment of circulating stromal cells precursors, in their differentiation towards different lineages, further favoring inflammation and angiogenesis, thus melanoma aggressiveness (Calvani et al. 2015).

\section{$\beta$-Blockers}

Several studies investigated the effects of $\beta$-blockers in melanoma cell proliferation and invasiveness. Propranolol has been shown to inhibit the increased metalloproteasedependent motility and the release of IL-6, IL-8 and VEGF induced by adrenaline and noradrenaline. (Moretti et al. 2013) In addition, propranolol has been shown to inhibit proliferation and induces apoptosis in primary cell cultures derived from human melanoma, both primary tumour and metastasis, and in melanoma cell lines (A375, Mewo, and Mel-CLS3) (Wrobel and Le Gal 2015). It is noteworthy that the cardioselective $\beta$-blocker metoprolol tartrate is not able to affect melanoma cell survival or proliferation to the same extent (Wrobel and Le Gal 2015). Propranolol has been extensively tested on the A375 melanoma cell line, two primary acral melanoma cell lines (P-3, P-6) and mice xenografts. Propranolol was able to inhibit viability of the different melanoma cell lines in a concentration and time dependent manner but had no effect on immortalized keratinocyte cell line. In addition, propranolol has been demonstrated to activate the intrinsic apoptosis pathway and inactivate the MAPK and AKT pathways, as it reduces the expression of Bcl-2, increases the expressions of Bax, cytochrome c, cleaved capase-9 and cleaved caspase-3, and down-regulated the levels of p-AKT, p-BRAF, p-MEK1/2 and p-ERK1/2 (Zhou et al. 2016). A better understanding of $\beta$-AR subtypes involvement in melanoma emerged from the use of selective antagonists. In order to unravel the role of $\beta 3$-ARs in mouse B16F10 melanoma cells, after demonstrating $\beta 3$-AR expression, the effects of $\beta 3$-AR blockers (SR59230A and L-748,337) were evaluated vs. propranolol or siRNAs targeting specific $\beta$-ARs. Beta3-blockers, likely via NO pathway, reduced cell proliferation, induced apoptosis and, differently form propranolol (Glasner et al. 2010) prevented the hypoxia-induced VEGF upregulation (Dal Monte et al. 2013).

SR59230A, a specific $\beta 3$-AR antagonist, counteracts the abovementioned metabolic shift with an increase in mtROS (Calvani et al. 2018). Notably, in embryonic stem cells, the increased mtROS are neutralized by a strong antioxidant activity, while in cancer stem cells this neutralization does not take place, with consequent reduction in tumor cell viability (Calvani et al. 2018). 
Initial evidence has been collected about the role of biased agonists, such as carvedilol, which are able to exert some activity as $\beta$-arrestin activators while blocking the $\beta$-ARs. In particular carvedilol has been shown to exert antiproliferative action on several tumoral cell lines, including melanoma Fem-x (Stanojkovic et al. 2005), and to be able to prevent the growth of A375 malignant melanoma xenografts in mice (Cleveland et al. 2018). On the other hand, some contrasting evidence emerged about the possible role of the $\beta 2-A R$, which when activated by (R,R')-4'-methoxy-1-naphthylfenoterol has been shown to inhibit proliferation and motility of melanoma cells (Wnorowski et al. 2015).

\section{In Vivo}

Recent evidence suggests that $\beta_{2}$-AR signaling in host immune cells orchestrates $\mathrm{CD}^{+} \mathrm{T}$ cell frequency and functional orientation within the tumor microenvironment. Evidence collected by means of different approaches aimed at reducing adrenergic activation (i. manipulation of ambient thermal environment; ii. $\beta$-blockers, iii. $\beta_{2}$-AR knockout mice) in mouse models of melanoma show that the decrease of $\beta$-AR signaling favored the conversion of tumors to an immunologically active microenvironment with increased frequency of effector $\mathrm{CD}^{+} \mathrm{T}$ cells, with relatively increased ratio to $\mathrm{CD}^{+}$regulatory $\mathrm{T}$ cell ratio (IFN $\gamma^{+} \mathrm{CD}^{+}$:Treg), and decreased expression of programmed death receptor-1 (PD-1) (Bucsek et al. 2017). Importantly, these features were associated with an increased efficacy of anti-PD-1 checkpoint blockade (Bucsek et al. 2017).

In B16F10 cells, neither isoprenaline nor propranolol affected cancer cell proliferation. Importantly, in B16F10 melanomabearing mice propranolol behaves as an antiproliferative according to a U-shaped biphasic dose-response curve. Low doses (10 and $20 \mathrm{mg} \cdot \mathrm{kg}^{-1} \cdot \mathrm{day}^{-1}$ ) significantly inhibit tumor growth, while higher doses exert progressively less effects. In addition, highdose propranolol stimulates melanoma arteriogenesis but with no effect on angiogenesis at any dose (Maccari et al. 2017). In immunodeficient mice transplanted with human melanoma cells, daily treatment with propranolol slows down tumor development (Wrobel and Le Gal 2015). According to RNA microarrays, quantitative PCR, and histochemistry findings, propranolol affects the expression of several genes involved in tumor angiogenesis, cell death, and proliferation (Wrobel and Le Gal 2015). Propranolol has been also investigated in the MT/Ret mouse model of melanoma, where its administration delayed primary tumor growth and metastases development, likely by decreasing cell proliferation and vessel density in both primary tumors and metastases (Wrobel et al. 2016). In addition, propranolol on the one side, reduced the infiltration of neutrophils in the tumor and, on the other side increased cytotoxic tumor infiltrating lymphocytes in the tumor stroma, with a similar pattern in both primary and secondary lesions (Wrobel et al. 2016). Daily treatment with propranolol has been shown to inhibit melanoma growth in
A375 xenografts where it also reduced Ki67, inhibited phosphorylation of AKT, BRAF, MEK1/2 and ERK1/2, thus activating the intrinsic apoptosis pathway and inactivating the MAPK and AKT pathways (Zhou et al. 2016). Furthermore, the growth of melanoma induced in mice by inoculation of B16F10 cells, was similarly reduced by intra-tumor injections of $\beta 3$-blockers SR59230A or L-748,337 that reduce cell proliferation and stimulate apoptosis that involves also endothelial cells and, consequently, decrease tumor vascularization (Dal Monte et al. 2013).

Finally, some evidence suggests synergistic anti-melanoma effects of propranolol with other drugs. First, it has been shown that the coadministration with etodolac is able to improve survival rates in $\mathrm{C} 57 \mathrm{BL} / 6 \mathrm{~J}$ mice were inoculated intrafootpad with syngeneic B16F10.9-melanoma, and to act as immunostimulant (Glasner et al. 2010; Goldfarb et al. 2011). Second, in a cell viability assay of A375 and P8 MM cell lines it has been shown a significant decrease of sunitinib IC50 when combined with propranolol (Kuang et al. 2017). Propranolol and sunitinib combination significantly downregulated phospho-Rb, phospho-ERK, Cyclin D1, and Cyclin E, with no effect on Bax, Bcl-2, or cleaved PARP expression. In A375 xenografts, combination of propranolol and low-dose sunitinib reduced the average tumor size of treated mice similar to high-dose sunitinib treated (Kuang et al. 2017). Some studies have also afforded the hypothesis that, similar to what observed in vitro, also in vivo different $\beta$ AR subtypes may exert differential roles. In a murine model of B16 melanoma it has been shown that, $\beta 1 / 2-A R$ knockout mice displayed increased intratumoral levels of both noradrenaline and $\beta 3$-ARs, increased tumor vascularization, decreased tumor cell proliferation and increased tumor cell apoptosis (Sereni et al. 2015). Importantly, $\beta 1 / 2-A R$ knockout mice also showed increased responsiveness to the intralesional injection the $\beta 3$-blocker L-748,337 (decrease in tumor growth, tumor vascular response, tumor cell proliferation, increase in tumor cell death) (Sereni et al. 2015). Importantly, in a mouse model of metastatic melanoma (B16-F10 melanoma cells transfected with red fluorescent protein, injected intravenously into syngenic C57BL/6 J mice to generate lung and liver metastases), plasma levels of adrenocorticotropin hormone, corticosterone and noradrenaline increased following a circadian pattern, being the two latters able to increase in vitro the expression and secretion of IL-6 in B16-F10 cells. In vivo inoculation of B16-F10 cells transfected with anti-IL-6-siRNA, treatment with a glucocorticoid receptor blocker or with propranolol, increased hepatic GSH while decreasing plasma IL-6 levels and metastatic growth (Valles et al. 2013).

\section{Clinical Evidence}

The possible impact of $\beta$-blockers on cancer progression and diffusion has been quite extensively investigated in last years. 
According to a recent review, searching for studies published up to September 1, 2017 and including 36 studies, which involve 319,006 patients, there was no evidence of an association between $\beta$-blocker use and overall survival, all-cause mortality, disease-free survival, progression-free survival, and recurrence-free survival. Notwithstanding, $\beta$-blocker use was significantly associated with longer overall survival only in melanoma (HR $=0.81,95 \%$ CI: $0.67-0.97$ ), ovarian and pancreatic cancer and better cancer-specific survival for several cancer types (HR $=0.78,95 \%$ CI: 0.65-0.95), including melanoma (Na et al. 2018). In a meta-analysis on $\beta$-blocker use and cancer prognosis, where studies which were deemed to include immortal time bias were not considered, a significantly higher overall survival (HR $0.81,95 \%$ CI $0.69-0.96$ ) among melanoma patients was observed. However, there was no melanoma-specific survival advantage (HR $0.92,95 \%$ CI $0.74-1.15)$. This finding suggests that the potential beneficial effects of $\beta$-blockers might primarily reflect non-cancer related positive effects, for instance on the course of cardiovascular comorbidities (Weberpals et al. 2016).

Up to date, no results have been collected through trials and our current knowledge is mainly founded on few retrospective observational studies (Table 2). Initial evidence has emerged from the observation that the use of $\beta$-blockers for concomitant diseases is associated with a reduced risk of progression of thick (Breslow thickness $>1 \mathrm{~mm}$ ) melanoma. In the cohorts, 30 patients had been prescribed $\beta$-blockers for 1 year or more, whereas the other 91 were untreated. After a median follow-up time of 2.5 years, tumor progression was observed in $3.3 \%$ of the treated subgroup and in $34.1 \%$ of the untreated subgroup, with $36 \%$ (95\% confidence interval (CI), $11 \%-$ $54 \%)(P=.002)$ risk reduction for each year of $\beta$-blocker use. It is noteworthy that no deaths were observed among patients who have taken $\beta$-blocker, in comparison to the 24 deaths registered among untreated patients (De Giorgi et al. 2011). After a median follow-up of 8 years of the two cohorts, with a median exposure to $\beta$-blocker use of 7.6 years, $30 \%$ of the patients in the treated group vs. $45 \%$ in the untreated group showed disease progression. Importantly, even after longer follow up the initial finding about the difference in deaths was observed, as in the treated group only $17 \%$ patients died from melanoma vs. 35\% in the untreated group (De Giorgi et al. 2017). The finding was confirmed by the same Authors investigating a larger population, including all consecutive patients diagnosed with melanoma between January 1993 and December 2009. Of the 741 consecutive patients with melanoma, 79 (11\%) were prescribed $\beta$-blockers for 1 or more years and 662 (89\%) were not untreated. The treated group had improved overall survival after a median followup of 4 years $(P=.005)$. For each year of $\beta$-blocker use, the risk of death was reduced by $38 \%$ (De Giorgi et al. 2013). More recently, a first prospective study has been performed administering off-label propranolol in patients treated for melanoma. Patients with histologically confirmed stage IB to IIIA cutaneous melanoma and no evidence of metastasis were considered eligible. At diagnosis, they were asked to take propranolol ( $80 \mathrm{mg}$ daily) as an off-label adjuvant treatment. Patients who agreed to use the propranolol enter the propranolol cohort, those who refused entered the no-propranolol cohort. Among the 53 patients included in the study, 19 entered the propranolol cohort, while 34 were enrolled in the nopropranolol cohort. The use of propranolol at the time of diagnosis was inversely associated with recurrence of melanoma, with risk reduction close to $80 \%$ for propranolol cohort (hazard ratio (HR), $0.18 ; 95 \% \mathrm{CI}, 0.04-0.89 ; P=.03$ ) after a median follow up of 3 years (De Giorgi et al. 2018). Similar findings were obtained retrieving data from Danish Cancer Registry and medical and administrative databases, including

Table 2 Main characteristics of clinical studies investigating the impact of $\beta$-blockers on melanoma

\begin{tabular}{|c|c|c|c|c|c|c|}
\hline Study design & Study direction & Country & Source of data & Sample size & $\begin{array}{l}\text { Follow up time } \\
\text { (median, years) }\end{array}$ & Reference \\
\hline \multicolumn{7}{|c|}{ Findings supporting a benefit from $\beta$-blocker treatment } \\
\hline Cohort & Retrospective & Italy & Clinical charts & 121 & 2.5 & De Giorgi et al. 2011 \\
\hline Cohort & Retrospective & Denmark & Administrative database & 4179 & 4.9 & Lemeshow et al. 2011 \\
\hline Cohort & Retrospective & Italy & Clinical charts & 741 & 4 & De Giorgi et al. 2013 \\
\hline Cohort & Retrospective & Italy & Clinical charts & 121 & 7.6 & De Giorgi et al. 2017 \\
\hline Cohort & Retrospective & US & Registry & 195 & Not reported & Kokolus et al. 2017 \\
\hline Cohort & Prospective & Italy & Clinical charts & 53 & 3 & De Giorgi et al. 2018 \\
\hline \multicolumn{7}{|c|}{ Findings not supporting a benefit from $\beta$-blocker treatment } \\
\hline Cohort & Retrospective & Germany/The Netherlands & $\begin{array}{l}\text { Administrative } \\
\text { database/registry }\end{array}$ & 709 & 3,25 & Livingstone et al. 2013 \\
\hline Case- control & Retrospective & Northern Ireland/UK & $\begin{array}{l}\text { Administrative } \\
\text { database/registry }\end{array}$ & 1876 & 7.5 & McCourt et al. 2014 \\
\hline Case-control & Retrospective & US & Clinical charts & 159 & NR & Failing et al. 2016 \\
\hline
\end{tabular}


4179 patients diagnosed with malignant melanoma. A total of $372(8.9 \%)$ patients with malignant melanoma were treated with $\beta$-blockers within 90 days of melanoma diagnosis. After adjustment for age and comorbidity index, HR for melanoma death was 0.87 (95\% CI: 0.64-1.20) and for all-cause mortality was 0.81 (95\% CI: 0.67-0.97) (Lemeshow et al. 2011). More recently, similar to preclinical results, a retrospective study has shown that metastatic patients who received immunotherapy had improved overall survival if they also received $\beta$-blockers (Kokolus et al. 2017).

It is worth noting that also negative findings have been reported. In a case-control study based on the U.K. Clinical Practice Research Datalink and cancer registry data, patients who received a new melanoma diagnosis between 1998 and 2010 were included. Cases, represented by patients with malignant melanoma with a melanoma-specific death, were matched on year of diagnosis, age and sex to four malignant melanoma controls. A nested case-control approach was used to investigate the association between postdiagnostic $\beta$ blocker use and mortality. $\beta$-blockers were prescribed after melanoma diagnosis to $20.2 \%$ of 242 cases and $20.3 \%$ of 886 matched controls with no association between $\beta$-blocker use postdiagnosis and cancer-specific death or all-cause mortality (McCourt et al. 2014). In addition, a study analyzing data from the Eindhoven Cancer Registry between January 1, 1998 and December 31, 2010, who were also registered with PHARMO record linkage system, identified a cohort of adult patients with cutaneous melanoma (Breslow thickness $>$ $1 \mathrm{~mm}$ ) who were matched on age and gender served as a control cohort. Two hundred and three of 709 eligible patients used $\beta$-blockers after melanoma diagnosis and the use of $\beta$ blockers was not associated with the risk of death (Livingstone et al. 2013). More recently, in a case control study including 159 adults who received ipilimumab for metastatic melanoma from 1 March 2011 through 31 December 2014, $\beta$-blockers, similar to other drugs, seemed to have no effects on the odds of experiencing a partial response or a complete response to ipilimumab (Failing et al. 2016).

\section{Conclusions}

Preclinical and clinical evidence has been accumulating about the involvement of $\beta$-ARs in melanoma progression. This involvement has been paralleled by the evidence that drugs targeting, read blocking, $\beta$-ARs may have a relevant role in the treatment of melanoma and in the control of its progression. Current knowledge proposes $\beta$-blockers as an opportunity for antitumor treatment in melanoma on the basis of positive findings collected in few observational studies, mostly performed in small cohorts of patients. It is important to underline that evidence collected by means of observational studies are, for intrinsic methodological reasons, affected by limitations and biases, such as selection bias (e.g. loss to follow up, confounding by indication) and more importantly immortal time bias. Accordingly, large double-blinded, randomized, clinical trials are needed in order to prove (or disprove) their claimed efficacy, identifying appropriate paradigms of treatment (e.g. type of $\beta$-blocker to be used, duration of administration, specific subtype of melanoma to be treated).

\section{References}

Algire GH, Legallais FY (1951) Vascular reactions of Normal and malignant tissue in vivo. IV The effect of peripheral hypotension on transplanted tumors. J Natl Cancer Inst 12:399-421

Algire GH, Legallais FY (1958) Growth and vascularization of transplanted mouse melanoma. In: The biology of melanomas. Academic Press, Inc, New York, pp 159-170

Baker JG (2005) The selectivity of beta-adrenoceptor antagonists at the human beta1, beta2 and beta3 adrenoceptors. Br J Pharmacol 144: $317-322$

Balligand JL (2013) Beta3-adrenoreceptors in cardiovascular diseases: new roles for an "old" receptor. Curr Drug Deliv 10:64-66

Bond RA, Bylund DB, Eikenburg DC, Hieble JP, Hills R, Minneman KP, Parra S (2019) Adrenoceptors: $\beta 3$-adrenoceptor. Last modified on 27/02/2019. IUPHAR/BPS Guide Pharmacol. http://www. guidetopharmacology.org/GRAC/ObjectDisplayForward?objectId= 30. Accessed 17 Apr 2019

Bucsek MJ, Qiao G, MacDonald CR, Giridharan T, Evans L, Niedzwecki B, Liu H, Kokolus KM, Eng JW, Messmer MN, Attwood K, Abrams SI, Hylander BL, Repasky EA (2017) $\beta$-adrenergic signaling in mice housed at standard temperatures suppresses an effector phenotype in CD8+ T cells and undermines checkpoint inhibitor therapy. Cancer Res 77:5639-5651

Calvani M, Pelon F, Comito G, Taddei ML, Moretti S, Innocenti S, Nassini R, Gerlini G, Borgognoni L, Bambi F, Giannoni E, Filippi L, Chiarugi P (2015) Norepinephrine promotes tumor microenvironment reactivity through $\beta 3$-adrenoceptors during melanoma progression. Oncotarget 6:4615-4632

Calvani M, Cavallini L, Tondo A, Spinelli V, Ricci L, Pasha A, Bruno G, Buonvicino D, Bigagli E, Vignoli M, Bianchini F, Sartiani L, Lodovici M, Semeraro R, Fontani F, De Logu F, Dal Monte M, Chiarugi P, Favre C, Filippi L (2018) ß3-Adrenoreceptors control mitochondrial dormancy in melanoma and embryonic stem cells. Oxidative Med Cell Longev 2018:6816508

Chen L, Tsai TF (2017) The role of $\beta$-blockers in dermatological treatment: a review. J Eur Acad Dermatol Venereol 32:363-371

Chidiac P, Hebert TE, Valiquette M, Dennis M, Bouvier M (1994) Inverse agonist activity of beta-adrenergic antagonists. Mol Pharmacol 45: 490-499

Cleveland KH, Yeung S, Huang KM, Liang S, Andresen BT, Huang Y (2018) Phosphoproteome profiling provides insight into the mechanism of action for carvedilol-mediated cancer prevention. Mol Carcinog 57:997-1007

Coelho M, Soares-Silva C, Brandão D, Marino F, Cosentino M, Ribeiro L (2017) $\beta$-Adrenergic modulation of cancer cell proliferation: available evidence and clinical perspectives. J Cancer Res Clin Oncol 143:275-291

Dal Monte M, Casini G, Filippi L, Nicchia GP, Svelto M, Bagnoli P (2013) Functional involvement of $\beta 3$-adrenergic receptors in melanoma growth and vascularization. J Mol Med 91:1407-1419

De Giorgi V, Grazzini M, Gandini S, Benemei S, Lotti T, Marchionni N, Geppetti P (2011) Treatment with $\beta$-blockers and reduced disease 
progression in patients with thick melanoma. Arch Intern Med 171: 779-781

De Giorgi V, Gandini S, Grazzini M, Benemei S, Marchionni N, Geppetti P (2013) Effect of $\beta$-blockers and other antihypertensive drugs on the risk of melanoma recurrence and death. Mayo Clin Proc 88: 1196-1203

De Giorgi V, Grazzini M, Benemei S, Marchionni N, Geppetti P, Gandini S (2017) $\beta$-Blocker use and reduced disease progression in patients with thick melanoma: 8 years of follow-up. Melanoma Res 27:268-270

De Giorgi V, Grazzini M, Benemei S, Marchionni N, Botteri E, Pennacchioli E, Geppetti P, Gandini S (2018) Propranolol for offlabel treatment of patients with melanoma: results from a cohort study. JAMA Oncol 4(2):e172908

Edlich RF, Rogers W, DeShazo CV Jr, Aust JB (1966) Effect of vasoactive drugs on tissue blood flow in the hamster melanoma. Cancer Res 26:1420-1424

Failing JJ, Finnes HD, Kottschade LA, Allred JB, Markovic SN (2016) Effects of commonly used chronic medications on the outcomes of ipilimumab therapy in patients with metastatic melanoma. Melanoma Res 26:609-615

Glasner A, Avraham R, Rosenne E, Bensih M, Zmora O, Shemer S, Meiboom H, Ben-Eliyahu S (2010) Improving survival rates in two models of spontaneous postoperative metastasis in mice by combined administration of a beta-adrenergic antagonist and a cyclooxygenase-2 inhibitor. J Immunol 184:2449-2457

Goldfarb Y, Sorski L, Benish M, Levi B, Melamed R, Ben-Eliyahu S (2011) Improving postoperative immune status and resistance to cancer metastasis: a combined perioperative approach of immunostimulation and prevention of excessive surgical stress responses. Ann Surg 253:798-810

Goldstein DS (2003) Catecholamines and stress. Endocr Regul 37:69-80

Guillino PM, Grantham FH (1961) Studies on the exchange of fluid between host and tumor. II. The blood flow of hepatomas and other tumors in rats and mice. J Natl Cancer Inst 27:1465-1491

Guillino PM, Grantham FH (1962) Studies on the exchange of fluid between host and tumor. III. Regulation of blood flow in hepatomas and other rat tumors. J Natl Cancer Inst 28:211-230

Hassan S, Karpova Y, Flores A, D'Agostino R Jr, Kulik G (2013) Surgical stress delays prostate involution in mice. PLoS One 8:e78175

Hirota K (2016) Adrenoceptor modulators and cancer progression. J Anesth 30:365-368

Jia Y, Li F, Liu YF, Zhao JP, Leng MM, Chen L (2017) Depression and cancer risk: a systematic review and meta-analysis. Public Health 149:138-148

Katzung BG (2012) Introduction to autonomic pharmacology in basic \& clinical pharmacology, 12th edn. The McGraw-Hill, New York

Kokolus KM, Zhang Y, Sivik JM, Schmeck C, Zhu J, Repasky EA, Drabick JJ, Schell TD (2017) Beta blocker use correlates with better overall survival in metastatic melanoma patients and improves the efficacy of immunotherapies in mice. Oncoimmunology 7: e1405205

Krizanova O, Babula P, Pacak K (2016) Stress, catecholaminergic system and cancer. Stress 9:419-428

Kuang X, Qi M, Peng C, Zhou C, Su J, Zeng W, Liu H, Zhang J, Chen M, Shen M, Xie X, Li F, Zhao S, Li Q, Luo Z, Chen J, Tao J, He Y, Chen X (2017) Propranolol enhanced the anti-tumor effect of sunitinib by inhibiting proliferation and inducing $\mathrm{G} 0 / \mathrm{G} 1 / \mathrm{S}$ phase arrest in malignant melanoma. Oncotarget 9:802-811

Leaute-Labreze C, Dumas de la Roque E, Hubiche T, Boralevi F, Thambo JB, Taïeb A (2008) Propranolol for severe hemangiomas of infancy. N Engl J Med 358:2649-2651

Lameshow S, Sørensen HT, Phillips G, Yang EV, Antonsen S, Riis AH, Lesinski GB, Jackson R, Glaser R (2011) $\beta$-Blockers and survival among Danish patients with malignant melanoma: a populationbased cohort study. Cancer Epidemiol Biomark Prev 20:2273-2279
Livingstone E, Hollestein LM, van Herk-Sukel MP, van de Poll-Franse L, Nijsten T, Schadendorf D, de Vries E (2013) $\beta$-Blocker use and allcause mortality of melanoma patients: results from a populationbased Dutch cohort study. Eur J Cancer 49:3863-3871

López-Sendón J, Swedberg K, McMurray J, Tamargo J, Maggioni AP, Dargie H, Tendera M, Waagstein F, Kjekshus J, Lechat P, TorpPedersen C, Task force on Beta-blockers of the European Society of Cardiology (2004) Expert consensus document on betaadrenergic receptor blockers. Eur Heart J 25:1341-1362

Maccari S, Buoncervello M, Rampin A, Spada M, Macchia D, Giordani L, Stati T, Bearzi C, Catalano L, Rizzi R, Gabriele L, Marano G (2017) Biphasic effects of propranolol on tumour growth in B16F10 melanoma-bearing mice. Br J Pharmacol 174(2):139-149

Marino F, Cosentino M (2013) Adrenergic modulation of immune cells: an update. Amino Acids 45:55-71

Maverakis E, Cornelius LA, Bowen GM, Phan T, Patel FB, Fitzmaurice S, He Y, Burrall B, Duong C, Kloxin AM, Sultani H, Wilken R, Martinez SR, Patel F (2015) Metastatic melanoma-a review of current and future treatment options. Acta Derm Venereol 95:516-524

McCourt C, Coleman HG, Murray LJ, Cantwell MM, Dolan O, Powe DG, Cardwell CR (2014) Beta-blocker usage after malignant melanoma diagnosis and survival: a population-based nested casecontrol study. Br J Dermatol 170:930-938

Min HY, Boo HJ, Lee HJ, Jang HJ, Yun HJ, Hwang SJ, Smith JK, Lee HJ, Lee HY (2016) Smoking-associated lung cancer prevention by blockade of the beta-adrenergic receptor-mediated insulin-like growth factor receptor activation. Oncotarget 7:70936-70947

Moretti S, Massi D, Farini V, Baroni G, Parri M, Innocenti S, Cecchi R, Chiarugi P (2013) $\beta$-Adrenoceptors are upregulated in human melanoma and their activation releases pro-tumorigenic cytokines and metalloproteases in melanoma cell lines. Lab Investig 93:279-290

Munabi NC, England RW, Edwards AK, Kitajewski AA, Tan QK, Weinstein A, Kung JE, Wilcox M, Kitajewski JK, Shawber CJ, Wu JK (2016) Propranolol targets hemangioma stem cells via cAMP and mitogen-activated protein kinase regulation. Stem Cells Transl Med 5:45-55

Na Z, Qiao X, Hao X, Fan L, Xiao Y, Shao Y, Sun M, Feng Z, Guo W, Li J, Li J, Li D (2018) The effects of beta-blocker use on cancer prognosis: a meta-analysis based on 319,006 patients. Onco Targets Ther 11:4913-4944

Pasquier E, Street J, Pouchy C, Carre M, Gifford AJ, Murray J, Norris MD, Trahair T, Andre N, Kavallaris M (2013) $\beta$-blockers increase response to chemotherapy via direct antitumour and anti-angiogenic mechanisms in neuroblastoma. Br J Cancer 108:2485-2494

Rains SL, Amaya CN, Bryan BA (2017) Beta-adrenergic receptors are expressed across diverse cancers. Oncoscience 4:95-105

Sanzo M, Colucci R, Arunachalam M, Berti S, Moretti S (2010) Stress as a possible mechanism in melanoma progression. Dermatol Res Pract 2010:483493

Schuller HM, Cole B (1989) Regulation of cell proliferation by betaadrenergic receptors in a human lung adenocarcinoma cell line. Carcinogenesis 10:1753-1755

Sereni F, Dal Monte M, Filippi L, Bagnoli P (2015) Role of host $\beta 1$ - and $\beta 2$-adrenergic receptors in a murine model of B16 melanoma: functional involvement of $\beta 3$-adrenergic receptors. Naunyn Schmiedeberg's Arch Pharmacol 388:1317-1331

Spiegel D (1994) Health caring. Psychosocial support for patients with cancer. Cancer 74:1453-1457

Stanojkovic TP, Zizak Z, Mihailovic-Stanojevic N, Petrovic T, Juranic Z (2005) Inhibition of proliferation on some neoplastic cell lines-act of carvedilol and captopril. Exp Clin Cancer Res 24:387-395

Steinkraus V, Nose M, Mensing H, Körner C (1990) Radioligand binding characteristics of beta 2-adrenoceptors of cultured melanoma cells. Br J Dermatol 123:163-170 
Tang J, Li Z, Lu L, Cho CH (2013) $\beta$-Adrenergic system, a backstage manipulator regulating tumour progression and drug target in cancer therapy. Semin Cancer Biol 23:533-542

Thaker PH, Han LY, Kamat AA, Arevalo JM, Takahashi R, Lu C, Jennings NB, Armaiz-Pena G, Bankson JA, Ravoori M, Merritt WM, Lin YG, Mangala LS, Kim TJ, Coleman RL, Landen CN, Li Y, Felix E, Sanguino AM, Newman RA, Lloyd M, Gershenson DM, Kundra V, Lopez-Berestein G, Lutgendorf SK, Cole SW, Sood AK (2006) Chronic stress promotes tumor growth and angiogenesis in a mouse model of ovarian carcinoma. Nat Med 12:939-944

Valles SL, Benlloch M, Rodriguez ML, Mena S, Pellicer JA, Asensi M, Obrador E, Estrela JM (2013) Stress hormones promote growth of B16-F10 melanoma metastases: an interleukin 6- and glutathionedependent mechanism. J Transl Med 11:72

Weberpals J, Jansen L, Carr PR, Hoffmeister M, Brenner H (2016) Beta blockers and cancer prognosis - the role of immortal time bias: a systematic review and meta-analysis. Cancer Treat Rev 47:1-11

Westfall TC, Westfall DP (2011) Adrenergic agonists and antagonists. In: Brunton LL (ed) Goodman \& Gilman's the pharmacological basis of therapeutics, 12th edn. The McGraw-Hill, New York

WHO-Skin Cancer (2019) https://www.who.int/uv/faq/skincancer/en/ index1.html. Accessed 11 Apr 2019

Wnorowski A, Sadowska M, Paul RK, Singh NS, Boguszewska-Czubara A, Jimenez L, Abdelmohsen K, Toll L, Jozwiak K, Bernier M, Wainer IW (2015) Activation of $\beta 2$-adrenergic receptor by (R,R')4'-methoxy-1-naphthylfenoterol inhibits proliferation and motility of melanoma cells. Cell Signal 27:997-1007

Wrobel LJ, Le Gal FA (2015) Inhibition of human melanoma growth by a non-cardioselective $\beta$-blocker. Invest Dermatol 135:525-531
Wrobel LJ, Bod L, Lengagne R, Kato M, Prévost-Blondel A, Le Gal FA (2016) Propranolol induces a favourable shift of anti-tumor immunity in a murine spontaneous model of melanoma. Oncotarget 7: $77825-77837$

Yang EV, Kim SJ, Donovan EL, Chen M, Gross AC, Webster Marketon JI, Barsky SH, Glaser R (2009) Norepinephrine upregulates VEGF, IL-8, and IL-6 expression in human melanoma tumor cell lines: implications for stress-related enhancement of tumor progression. Brain Behav Immun 23:267-275

Yap A, Lopez-Olivo MA, Dubowitz J, Pratt G, Hiller J, Gottumukkala V, Sloan E, Riedel B, Schier R (2018) Effect of beta-blockers on cancer recurrence and survival: a meta-analysis of epidemiological and perioperative studies. $\mathrm{Br} \mathrm{J}$ Anaesth 21:45-57

Zahalka AH, Arnal-Estapé A, Maryanovich M, Nakahara F, Cruz CD, Finley LWS, Frenette PS (2017) Adrenergic nerves activate an angio-metabolic switch in prostate cancer. Science 358:321-326

Zhang D, Ma QY, Hu HT, Zhang M (2010) $\beta 2$-adrenergic antagonists suppress pancreatic cancer cell invasion by inhibiting CREB, NFKB and AP-1. Cancer Biol Ther 10:19-29

Zhou C, Chen X, Zeng W, Peng C, Huang G, Li X, Ouyang Z, Luo Y, Xu X, Xu B, Wang W, He R, Zhang X, Zhang L, Liu J, Knepper TC, He Y, McLeod HL (2016) Propranolol induced G0/G1/S phase arrest and apoptosis in melanoma cells via AKT/MAPK pathway. Oncotarget 7:68314-68327

Publisher's Note Springer Nature remains neutral with regard to jurisdictional claims in published maps and institutional affiliations. 